\title{
The role of interpretation of existing practice in normative political argument
}

\author{
Lægaard, Sune
}

Published in:

Critical Review of International Social and Political Philosophy

DOI:

10.1080/13698230.2017.1403128

Publication date:

2019

Document Version

Early version, also known as pre-print

Citation for published version (APA):

Lægaard, S. (2019). The role of interpretation of existing practice in normative political argument. Critical Review of International Social and Political Philosophy, 22(1), 87-102. https://doi.org/10.1080/13698230.2017.1403128

\section{General rights}

Copyright and moral rights for the publications made accessible in the public portal are retained by the authors and/or other copyright owners and it is a condition of accessing publications that users recognise and abide by the legal requirements associated with these rights.

- Users may download and print one copy of any publication from the public portal for the purpose of private study or research.

- You may not further distribute the material or use it for any profit-making activity or commercial gain.

- You may freely distribute the URL identifying the publication in the public portal.

\section{Take down policy}

If you believe that this document breaches copyright please contact rucforsk@kb.dk providing details, and we will remove access to the work immediately and investigate your claim. 


\title{
The Role of Interpretation of Existing Practice in Normative Political Argument
}

Sune Logaard, Department of Communication and Arts, Roskilde University, Denmark

The official version of this paper was published in Critical Review of Social and Political

Philosophy, volume 22, issue 1, pages 87-102, 2019. DOI: 10.1080/13698230.2017.1403128

Link to full paper:

https://www.tandfonline.com/doi/abs/10.1080/13698230.2017.1403128?journalCode=fcri20

\begin{abstract}
In political theory concerned with normative evaluations and prescriptions facts can play two roles:

1) Facts can be of importance for the application of general normative principles to particular cases, and 2) facts can be of importance for the justification of normative principles as such. Political realists are critical of the first role, which they take to express a conception of political theory as 'applied moral philosophy'. The paper investigates how interpretation of existing practices can be part of the second justificatory role, as suggested by proponents of different versions of contextualism and practice-dependence. The paper focuses on Andrea Sangiovanni's methodological claims about social interpretation to illustrate both how facts can be part of the justification of principles and how interpretation is also faced with a number of problems as a way of justifying normative principles. The paper finally argues that some of these problems can be avoided if one considers the two roles together; what enables interpretation of facts as part of the justification of normative principles precisely is that application and justification are not separate exercises.
\end{abstract}

\section{Keywords}

Political Philosophy, Political Theory, Practice-dependence, Methodology, Interpretation

\section{Introduction}

Facts can play two roles in political theory concerned with normative evaluations and prescriptions: They can be part of the application of general normative principles to particular cases and of the justification of normative principles as such. This article investigates how interpretation of existing practices can be part of the second justificatory role. This is not a new idea. It is found in Michael Walzer's Spheres of Justice (1983), some see it as a fundamental part of Rawlsian methodology (James 2005, but see Meckled-Garcia 2013), and it has been invoked by many self-described contextualists (e.g. Miller 2013, Favell 2014). It has nevertheless not been spelled out in much 
detail exactly how interpretation can get us from facts about existing practices to justifications of normative principles.

Andrea Sangiovanni's 'practice-dependence thesis' articulates the stages of such an interpretation. He thereby addresses the question of how to get from facts to normative principles. I will consider the practice-dependence thesis as a view about how facts are relevant for the justification of principles and as a general thesis rather than as a specific intervention in the debates about global justice in which it was originally articulated. I will therefore discuss it in relation to different kinds of cases than the ones to which Sangiovanni himself applies it in order to assess it.

I first present two different roles facts can play in normative political argument: as part of application and as part of justification. I subsequently sketch the 'practice-dependence thesis' and Sangiovanni's model for how interpretation of institutions enters into justification of principles. I then use a concrete institutional example, namely the Danish regulation of religion, to illustrate institutional interpretation in practice and what problems Sangiovanni's model encounters. I conclude that the practice-dependence thesis is problematic but that many of the ideas about factrelevance that motivates it can be captured within a reflective equilibrium methodology that combines application and justification.

\section{Two Roles of Facts in Political Theory}

Given an understanding of political theory as the activity of trying to provide systematically justified answers to normative questions, the question about the relationship between facts and norms becomes pressing and interesting. We can distinguish between two views about the role facts play in normative political argument: First, facts are involved in the application of normative principles to particular cases (Lægaard 2015, p. 266). Justification here consists in deriving a normative claim regarding a specific case from a more general normative principle. The clearest example of this is act utilitarianism, according to which normative claims about what we should do are justified with reference to the general principle that we should maximise the total sum of welfare. But a similar application model holds for many other normative theories with different justificatory principles, including avowedly anti-utilitarian theories such as Rawls's theory of justice.

The role of facts in the application model is to explain what the general normative principles imply for specific cases. There is a two stage sequence: first we have normative principles valid for a range of cases, then we introduce the facts about a specific case that are relevant from the point of view of the principles (in utiltarianism, facts about how different available courses of action affect the sum of welfare, in Rawls's theory of justice, facts about how different ways of ordering society's basic structure affects the social and economic shares of the worst off). Only then do we know what we should do in the particular case. Facts, according to the application model, are necessary for the application of theories to cases. 
This view of the role of facts might seem uncontroversial. Facts about specific cases seem necessary for determining what general principles imply for specific cases (Sangiovanni 2016, p. 3). Nevertheless, the application model has been criticised by political realists, who take it to express a conception of political theory as 'applied moral philosophy' (Hall 2015). Realists object to what they see as a reduction of politics to morality because they conceive of the political as distinct from other spheres.

On another view about the role of facts in political theory, facts are not only relevant for the application of principles to particular cases, but also for the justification of the normative principles as such. According to this justification model, facts are involved not only at stage two but already at stage one.

There is not necessarily anything controversial about involvement of facts in justification of principles; facts about the sentience, ability to suffer, vulnerability, mortality and ability to plan of human beings are arguably crucial to the justification of principles that direct us to maximise welfare, prevent harm, protect human life or respect choices. But this kind of fact involvement in justification is conditional and serves the function of triggering normative principles (MeckledGarcia 2013, p. 107, Sangiovanni 2016, pp. 5-6): the fact that humans and other sentient beings can suffer, for utilitarians, is part of the explanation why we should be concerned with the welfare of sentient beings, i.e. why the utilitarian principle is triggered in cases where our actions affect sentient beings. But it is not this fact that justifies the axiological claim that welfare is good or the normative claim that we should maximise welfare.

My distinction between the application model and the justificatory model is not identical to Sangiovanni's distinction between 'mediated deduction' and 'instrumental' modes of application of principles (2016, pp. 14-15). First, my distinction is not between two different modes of applying higher order principles, but between two ways in which facts may be relevant to normative political arguments.

Secondly, Sangiovanni assumes that whereas the instrumental mode aims for all things considered judgments, mediated deduction only aims to identify one relevant principle among possible others. But both the application model and the justification model are compatible with either reading: For value monists, both models will aim for all things considered judgments, whereas for value pluralists, both models can aim to identify the implications of or justify one among several principles, respectively.

Thirdly, the application model is not necessarily instrumental. On the application model, the conclusion of a political argument is a claim about what to do in or think about a particular case, which is an implication of a more general normative principle. Just because one derives implications from a more general principle of justice about how a particular practice should be reformed in order to be just, the practice does not thereby become 'an instrument for realizing a set of higher-level principles' (Sangiovanni 2016, p. 15). Our reasons for having a practice are not usually that it serves as a means to realise justice; rather, we have practices for other reasons, and 
once we have one, we need to make sure that it is just. Even on the application model, justice is usually a constraint on practices that are not primarily instruments for realising justice.

The justification model only becomes controversial if facts enter into the justification of normative premises in a not merely conditional or triggering way. The claim has to be that facts are involved in a way that explains the normative content of principles rather than merely the scope within which the principles apply. It is a version of this kind of claim I will discuss now.

\section{Practice-dependence}

Sangiovanni's claim is that 'existing institutions and practices ... play a crucial role in the justification of a conception of justice rather than merely its implementation' (Sangiovanni 2008, p. 137). The practice-dependence thesis states that 'The content, scope, and justification of a conception of justice depends on the structure and form of the practices that the conception is intended to govern' (Sangiovanni 2008, p. 138). So the thesis is a species of the justification model and not merely the application model. ${ }^{1}$

Sangiovanni's thesis suggests that the same higher level principles, e.g. ideas about equal respect or reciprocity, can mean different things for different kinds of institutions or practices, depending on the nature of the relations that such institutions place people in. Any discussion of justice therefore has to include an interpretation of the institutions or practices in question. Sangiovanni mainly exemplifies this point with reference to international institutions such as the WTO, EU or international human rights. The practice-dependence thesis accordingly has mostly been discussed in debates about global justice. The upshot of the thesis here is to constrain the scope of certain principles (Meckled-Garcia 2013, p. 101), e.g. to explain why egalitarian distributional principles apply within nation-states but not in international institutions. The thesis is nevertheless not specific to debates about international justice but is supposed to hold for any political theory aiming to evaluate existing practices (Sangiovanni 2016, p. 20).

To make normative judgments about the justice of a particular practice we first need an interpretation of 'the point and purpose' of the institution or practice (Sangiovanni 2008, p. 141). Sangiovanni distinguishes between 'descriptive' and 'critical' interpretative stances in relation to a given 'institutional system': A descriptive interpretation attempts to explain what a particular institutional system is by explaining 'how its various components fit together as parts of an integral whole'. The aim is to identify 'the unity of the institutional system in terms of the point or purpose of the practices that make it up', which enable us to make sense of institutions (Sangiovanni 2008, p. 142). This claim reiterates the common view about standards of interpretation that an

\footnotetext{
${ }^{1}$ Whereas he originally presented the distinction between 'practice-dependence' and 'practice-independence' as different approaches to political theory generally, Sangiovanni now rather sees them as two different modes of applying higher-level principles and values to social practices (Sangiovanni 2016, p. 15). This difference does not affect the methodological prescriptions about the relevance of facts at the stages of interpretation that I am concerned with.
} 
interpretation has to ascribe meaning to some object of interpretation in a way that provides the most coherent explanation for the different parts of the object of interpretation.

Critical interpretations, on the other hand, do not merely ask what the institutional system is, but what it should be. The practice-dependence thesis claims that such a normative judgment 'must itself depend on the character of the institutional system as it actually is, and hence on a description cum interpretation of it' (Sangiovanni 2008, p. 144). This is not merely a matter of applying already given principles, where the normative premises of the justification for the judgment are not affected by the nature of the institution or practice they are applied to, but rather a matter of what Sangiovanni now calls 'mediating deduction', i.e. that the point and purpose of the institution or practice co-determines what the higher order normative principles mean in this particular case (Sangiovanni 2016, p. 20).

How should political theorists proceed in practice according to the practice-dependence thesis? Sangiovanni identifies three stages of interpretation: ${ }^{2}$ The first 'pre-interpretive' stage is concerned with identifying a shared object of interpretation to delineate what features the subsequent interpretation should make sense of. The properly 'interpretive' stage then first seeks to determine the point and purpose of the institution in question, and secondly, to reconstruct what reasons the participants in the practice might have for affirming its basic rules, procedures, and standards (Sangiovanni 2008, p. 148).

The third, 'post-interpretive' stage, moves to the critical and normative assessment of the institution. On the basis of the interpretation of the point and purpose of the institution and the reasons that participants have for affirming them, one now asks how this affects the meaning of, e.g., principles of justice, legitimacy or reciprocity for this particular institution. The practicedependence thesis tells us to work out the specific meaning of higher order principles or values in light of the interpretation of the point and purpose of those institutions, the claim being that many principles and values would lack a determinate content or application without the constraints provided by the interpretive step (Sangiovanni 2008, p. 150).

Sangiovanni affirms several requirements on interpretation. First, 'the idea of an institutional system taken as an integral whole' is crucial; an interpretation of a particular component of an institutional system only counts as successful if it fits the system as a whole (Sangiovanni 2008, p. 143). This assumption of unity is necessary because the success of an interpretation must be judged relative to how it makes sense of different parts of some whole. So if it is unclear what the whole is, then it is unclear what counts as a good interpretation of the parts (and vice versa).

Sangiovanni secondly invokes a standard principle of interpretative charity according to which 'the interpreter seeks to understand the institution (or set of institutions) as an integral whole, whose parts work together in realizing a unique point and purpose.' (Sangiovanni 2008, pp. 148-149) This assumption of coherence, i.e. that interpretation aims at identifying a point and purpose that makes

\footnotetext{
${ }^{2}$ Sangiovanni's stages of interpretation follow Dworkin (2011, p. 131). But see Meckled-Garcia (2013) as to differences between practice-dependence and Dworkinian interpretivism.
} 
sense of the different parts of a system as elements of a whole, articulates what interpretation means.

\section{A Test Case for Practice-dependence: Regulation of Religious Communities}

Criticisms of practice-dependence have either tended to focus on the global justice debates in relation to which the thesis was formulated (e.g. Valentini 2011) or have provide a general theoretical criticism of the very idea of practice-dependence (e.g. Meckled-Garcia 2013). I will rather focus on the practical methodological implications of the thesis and illustrate how a practicedependent political theory following the noted interpretative approach encounters a number of problems.

I will do this in a way faithful to the spirit of (or at least not begging the question against) the practice-dependence thesis, namely by focusing on a particular practice or institutional system and go through Sangiovanni's stages of interpretation in relation to this particular case. My example concerns the Danish regulation of religious communities. This example differs from standard examples from the global justice debates, such as the WTO or EU, along a range of dimensions.

The practice-dependence thesis is a general thesis not only applying to international institutions (cf. the examples mentioned by Sangiovanni 2008, p. 143). So discussion of the thesis should include a broader range of examples than only international institutions. Regulation and recognition of religious communities is a central issue in European debates over multiculturalism. Many multiculturalists are also avowed contextualists, by which they mean that facts about the specific contexts are of central importance to normative assessments (cf. Lægaard 2015). It is therefore interesting to apply the practice-dependence thesis to a multicultural example, since it might explain how facts about the specific contexts are relevant to the political theory of multiculturalism. But this kind of case also illustrates some of the problems faced by the practice-dependence thesis clearer than the standard international examples.

Denmark has a constitutionally established church, which the state is committed to supporting, and freedom of religion and association. Beyond this, the constitution only says that the rules regulating the established church and other religious communities shall be laid down by statute, which, curiously, has never happened systematically. Instead specific laws have been passed on quite particular issues such as election rules for parish councils within the established church, over tax exemptions for religious communities outside the established church, to rights for recognised and approved religious communities outside the established church to conduct legally valid marriages (see Lægaard 2012).

Several of the central elements of this system of regulation, namely the governance of the established church and the notions of recognised and approved religious communities outside the established church, are neither set down in the constitution nor are they products of legislative acts; they rather have emerged informally through evolving administrative practice and through references in secondary legislation, such as the marriage act. The established church is in principle 
governed by the minister of ecclesiastical affairs in the same way as the state church was during absolutism (although there is a practice of restraint on the part of the minister, which also lacks any constitutionally or statuary basis). The criteria for approval of religious communities outside the established church have gradually developed administratively and subsequently been systematised by a non-elected panel of experts under the ministry.

The state collects church tax on behalf of the church from all members and additionally provides financial support funded through ordinary taxation levied on members and non-members alike. Recognised and approved religious communities receive no direct support, but are eligible for tax exempt status, just as donations by their members are deductible.

What should a political theorist assessing the way in which the Danish state regulates and recognises religious communities do according to the practice-dependence thesis? This would be an assessment of whether the system is sufficiently just and, if not, how it should be reformed. Political theory involves systematic justifications for such normative claims, which will have to include references to facts about the system, simply because it is about this system rather than, e.g., the American system. This is merely the kind of fact involvement characteristic of the application model. In a practice-dependent assessment facts will also have to enter into the justification for the normative premises of the justification (the mediating principles whose content is partly determined by the point and purpose of the practice in question). These facts about the point and purpose of the practice will have to be established through interpretation of the practice.

\section{Identifying the Object of Interpretation}

According to Sangiovanni's stages of interpretation, one first needs to identify the object of interpretation, which should be an institutional system. This is a 'set of formal and informal rules, norms, and decision-making procedures regulating a political or social activity' which 'defines the basic division of social opportunities and advantages in the competitive struggle for resources' (Sangiovanni 2008, p. 142).

The Danish system fits this characterisation of an institutional system: The practice of religion is a social opportunity that can be hindered or furthered by the regulatory framework. Insofar as the regulation also includes positive recognition, as the Danish system does both symbolically, financially, and in terms of delegation of legal powers, it also involves advantages and therefore a potential competition, e.g. whether religious establishment of a particular church can be accepted. In the Danish case there are both formal and informal rules that might be central to the institutional system regulating religious communities. But already at this point we run into a problem, for it is not quite clear which rules to include as parts of the system.

One question concerns the extent of the institutional system: Is there for instance one institutional system regulating and recognising all religious communities, including both the established church and other religious communities, or rather two separate institutional systems, one for the established church and one for recognised and approved religious communities? It might 
seem obvious that there is only one system, since both the established church and the recognised and approved religious communities are organised religious communities, all of which are recognised in some way by the state.

But there is actually a lot to say for the opposite view: The established church is recognised by the constitution whereas other religious communities are not; the established church receives state funding whereas others religious communities rather get tax exemptions; the established church is governed by the minister of ecclesiastical affairs and its internal affairs are subject to decisions taken in parliament, whereas other religious communities are private associations; the established church is administered under the ministry of ecclesiastical affairs whereas the recognised and approved religious communities are administered by the tax authorities, in matters regarding tax exemptions, whereas matters regarding approval and rights to conduct marriages used to fall under the ministry of social affairs and the interior.

The example thus illustrates a problem regarding the identification and delimitation of the system to be interpreted: In many cases, it is far from obvious or uncontroversial (pace Sangiovanni 2008, p. 148) how to identify and delimit the institutional system to be interpreted. ${ }^{3}$ This problem is often not as apparent in the standard examples concerning international institutions, which usually have a pretty clear and explicit delimitation. But in many other cases, this is not at all the case. The case of the Danish regulation of religious communities illustrates this, which arguably is the rule rather than the exception in most areas of politics.

One might respond that the delimitation of the object of interpretation is a pragmatic decision which in cases like this can go either way if only people agree on what they are talking about. Such a pragmatic approach seems sensible, since interpretation might have different purposes (Dworkin 2011). But for the purpose of practice-dependent political theory, it is problematic. The delimitation of the object of interpretation is important for assessments whether a given interpretation is a good interpretation. This in turn is important because the point and purpose of an institutional system codetermines what justice means for this institution. Whatever justice is, it cannot vary according to purely pragmatic choices. So if the practice-dependence thesis holds, there has to be a right answer as to how to delimit any given institutional system, otherwise justice becomes indeterminate and arbitrary.

The practice-dependence theorist cannot respond that general principles of justice determine how to identify and delimit institutional systems for the purpose of assessments in terms of justice. What motivates the practice-dependence thesis is that higher level principles are indeterminate. We do not know how higher-level principles and values bear on given practices (Sangiovanni 2016, p. 15). This is why we need mediating principles, which are more determinate and apply directly to practices because they partly depend on interpretations of practices. Therefore proponents of practice-dependence cannot appeal to higher level principles of justice to determine the justice-

\footnotetext{
${ }^{3}$ This problem is parallel to the challenge facing contextualism concerning how to delimit the relevant context.
} 
relevant interpretation of practices, for this would contradict the reason for adopting the practice dependence-thesis in the first place (Meckled-Garcia 2013, p. 103).

\section{Interpreting the Point of an Institution}

Following on the pre-interpretative stage of identifying the object of interpretation one moves to the properly interpretive stage, which seeks to determine the point and purpose of the institution in question. The interpretation should be guided by the principle of charity and its assumption of coherence, which aims to understand the institution as an integral whole, whose parts work together in realising a unique point and purpose.

What might the point and purpose of the Danish regulation of religious communities be? It now becomes clear what difference the delimitation at the pre-interpretative stage makes. What is the most plausible interpretation differs if we conceive of the Danish regime as one or as two systems. If we conceive of it as two systems, the system regulating religious communities other than the established church looks very egalitarian (the same criteria for approval are applied to all and are fairly impartial), it extends recognition and privileges to religious communities on an equal basis.

If we rather conceive of the Danish regime as one system, then it is highly inegalitarian (it treats the established church and all other religious communities radically differently), it seems to involve forms of mis-recognition, since the other religious communities are only given some of the privileges extended to the established church (and only insofar as they resemble the parish-structure of the established church), and it seems based on a positive evaluation of Evangelical-Lutheran doctrine over other religions.

These two interpretations are only based on some of the outward characteristics of the system. Any good interpretation should arguably also take account of the intentions informing the system. Here we encounter another problem. Whereas the point and purposes of international organisations are often quite clear and explicitly stated, because such institutions are created through international negotiations resulting in founding documents and explicitly laid out purposes, many other political institutions, like the Danish system, lack many of these features. As noted, the system has developed gradually, mainly through administrative decisions, has not been settled constitutionally and has rarely been the object of parliamentary debates on the system as a whole. It is even unclear which actors are central to the definition of the system.

In such cases, arguably quite common in domestic politics, the interpretative principle of charity, however reasonable as a general rule of interpretation, might not only be hard to apply - it might lead to wrong results. The assumptions of unity and coherence force us to impute a point and purpose and unity to the institution which it might lack, both as a matter of formal features, historical development, intentions and practice. In such cases, any claim about what constitutes the point and purpose of an institution is really a political attempt to capture the definitorial power over the institution. 
This once again poses a problem for practice-dependence: Either assessment of the system in terms of justice becomes impossible, since justice depends on mediating principles that cannot be had, because they require a unitary point and purpose. Or there is as much disagreement about the interpretation of a practice as about the assessment of it, in which case the former does not contribute to agreement on the latter, or, even more worryingly, where justice depends on which political party actually manages to impose its interpretation (Valentini 2011, p. 407).

\section{Interpreting Participants' Reasons}

At the interpretative stage we should also reconstruct what reasons the participants in the practice might have for affirming its basic rules, procedures, and standards. But this also poses problems for practice-dependence.

First, it is actually unclear who the participants are - are we supposed to focus on individual persons (members of religious communities) or on the individual religious communities and their representatives, who are the immediate participants in the system, since it is they who are approved, get tax exempt status and are delegated powers? This again makes a big difference for the interpretation; institutional actors' reasons for participating in a system that partly or wholly constitute them as institutions (e.g. as approved religious communities) are quite different from the reasons individual believers have for getting married within their religious community. Once again, the difference between these two interpretative perspectives cannot be settled by appeal to higher order principles of justice, since this would contradict the reason for practice-dependence.

Secondly, no matter who one takes as participants, it is quite difficult to say much about the reasons participants might have for affirming the practice. Participants might actually not have any reasons for participating - they might just be doing it - or they might participate in and affirm the rules of the system, but for irrelevant reasons. Immigrant members of religious minorities might for instance affirm the system because it provides a much higher degree of religious freedom as well as public recognition than they enjoyed in their country of origin. But this comparative assessment, even if true, seems irrelevant to understanding what the point and purpose of the system itself is.

Thirdly, participants' reasons for affirming the system might differ from and even contradict the point and purpose of the system as interpreted on the basis of the system's formal features (Meckled-Garcia 2013, pp. 98, 100). A religious minority might affirm the Danish system because it offers them positive recognition, which they might think is an element of equality. But both on the basis of the formal features of the system and on the basis of prominent views about what the rationale of the system is, the whole point and purpose may rather be to uphold religious inequality, e.g. to purchase the continuation of Lutheran establishment by offering religious freedom to other religious communities. Again, which interpretation one assumes makes a big difference for the assessment of the system in terms of justice.

One might respond that the focus on participants' reasons should not pick out their actual contingent motives but rather what would justify the system from the point of view of participants. 
This shift of focus could solve the problems of identifying the relevant reasons for affirmation and would make sense in light of the aim of providing a practice-dependent assessment in terms of justice.

But this response is not open to the practice-dependent theorist either. The interpretation is still supposed to be descriptive, i.e. to tell us what reasons participants in fact have. This stage concerns what the system is, not whether it is normatively justifiable, which is the task for the postinterpretative stage. The move from actual motivation to justifiability would presuppose a stand on which features of the system are relevant for the purpose of justifiability, and this is exactly what practice-dependence assumes we cannot have independently of an interpretation of the practice to be assessed. Therefore the interpretation cannot, on pain of circularity, depend on a normative notion of justifiability.

\section{Deducing Mediating Principles}

Finally, at the third, post-interpretive stage, one asks how the interpretation of the point and purpose of the institution and the reasons participants have for affirming it affects the meaning of justice for this particular institution. The practice-dependence thesis tells us to 'work out', 'derive' or deduce' mediating principles of justice in light of the interpretation of the point and purpose of those institutions, which constrain the content and scope of mediating principles (Sangiovanni 2008, p. 150,2016 , pp. 16-17, although he also rejects the characterisation of how mediating principles are arrived at as a matter of 'derivation' on 2016, p. 19). The question is how this 'derivation' proceeds and which role facts about the point and purpose of the institution play in it?

Practice-dependent theorists should enquire how institutions form relations, enable interaction, institute interdependence and give rise to demands for justice between participants. But asking questions is not tantamount to 'derivation' or 'deduction' and does not tell us how the answers to such questions enter into the justification of mediating principles. Sangiovanni sketches a schema for 'mediated deduction' different from direct application of general principles to a specific case (Sangiovanni 2016, p. 17). But the schema does not show how interpretation of practices enters into the derivation of principles; it simply claims that the appropriate mediating principle is grounded by the nature and structure of the interaction characteristic of the practice in question. Sangiovanni subsequently acknowledges that there is a question of how to 'get from' higher level principles to mediating principles (2016, p. 18), but he simply answers this question by restating the claim that the justification of a mediating principle for a practice requires an interpretation of the practice. But this is exactly the claim in need of both explanation (how it works) and justification (why we should think this).

So the presentation of the practice-dependence thesis and mediated deduction does not explain how assessments of particular institutions like the Danish system depend on interpretation of the system. How could practice-dependence affect the normative assessment of the Danish system? Consider two possible normative judgments: 
1. The system is unjust because it upholds establishment of one faith, which is an unjust inequality, and involves the state in recognition of other religious communities, which breaches state neutrality; this should be rectified by dis-establishment and removal of all official recognition of religious communities.

2. The system is unjust because it treats religious communities differently, which is an unjust inequality; this should be rectified by instituting multi-faith establishment with equal support by the state for all religious communities as well as non-religious world-views.

If practice-dependence holds, the justifications of such normative claims have to fulfil two requirements:

a) the justification must include non-redundant reference to the point and purpose of the system, and

b) this reference cannot merely be for the purpose of applying higher-order principles directly to the case (along the application model), but must be necessary in order to give content and scope to mediating principles that are the necessary immediate normative premises for the justifications.

These requirements rule out justifications for claims like 1. and 2. on the basis of general requirements of state neutrality and equality coupled with empirical statements that the Danish system is non-neutral and/or upholds inequality. According to practice-dependence, we cannot say that justice rules out establishment, no matter how blatant the non-neutrality or inequality it involves; we can only make such judgments if they are justified with reference to a mediating principle of justice whose content and scope itself depends on and takes account of the point and purpose of the system in question.

These requirements can have restrictive and conservative normative implications and rule out fundamental objections such as 1 . and 2. above. If normative assessment of a system has to proceed from principles that depend on and take account of the system's purpose, how can the assessment reject the system altogether, as 1 . and 2. do?

Even if practice-dependence did allow for such fundamental normative criticisms, how can it justify one fundamental criticism over another, e.g. 2. over 1.? Both reject core features of the existing system, but they do so in favour of radically different alternatives. If the normative premises for selecting prescriptions depend on the existing system, how can one prescription rather than another be justified? Since the alternatives are so different, they are surely not equivalent from the point of view of justice, so a justification in terms of justice should be able to rank one over the other.

If one responds that in this case it is simply the system itself that is unjust and therefore it should be fundamentally changed, it is unclear what work, if any, the practice-dependence thesis is doing. How is such a claim justified with reference to mediating principles that depend on the point and purpose of the existing system? So the practice-dependence thesis faces a dilemma: Either it has to condone fundamental features of existing institutions that might otherwise be though unjust 
or it has to admit many exceptions to the practice-dependence thesis or that it is really just a variation of the application model.

\section{Conclusion: Reconciling Application and Justification}

I have argued that the practice-dependence thesis faces several problems which threaten to make justice indeterminate or arbitrary, to misunderstand institutions and to undermine normative assessments. If the justification model is abandoned for these reasons, this leaves us with some version of the application model. Political realists, contextualists and practice-dependent theorists alike will oppose this, both because they object to the application model and because facts surely are important to political theory. In conclusion I will address these worries.

The application model does not reduce politics to morality; it merely presupposes that there are normative questions about politics. Most realists acknowledge this, since they themselves use normative categories such as freedom and legitimacy (e.g. Williams 2005).

Nor is the application model tantamount to applied moral philosophy, since the model says nothing about the nature of the normative principles at stage one. These might be moral principles (like utilitarianism or Kantian imperatives), but they might also be what at least some realists might recognise as distinctively political principles. The application model only concerns how one applies general normative principles to particular cases, not the separate question about the nature or justification of the principles.

The application model mainly becomes controversial if supplemented with the claim that facts are only relevant at the second stage, and it leaves many of the central questions in the realistmoralism debate open, since they concern the nature and justification of the principles at the first stage.

Why nevertheless oppose the application model? Sangiovanni suggests that this is because the alternative to practice-dependence is the view that the justification for the conclusions of applied political arguments 'flows entirely from the fact that ... you have independent reasons for believing' that the normative premises of applied political arguments is 'the foundational principle of political morality' (2016, p. 18). What does 'independent reasons' and 'foundational principle' mean here? Sangiovanni's formulations suggest that the alternative is some a priori form of rationalist foundationalism regarding justice. But the application model is not committed to this at all. It only says how principles should be applied, not what their status or justification is.

An alternative to a priori foundationalism is reflective equilibrium as proposed by John Rawls (1999), where principles are justified through the coherence of their implications with considered judgments about a range of cases. According to reflective equilibrium, there are no 'foundational principles, only more or less general normative judgments, and justification is holistic rather than foundational. 
Sangiovanni seems to assume that the application model (what he calls the instrumental mode) is something else than reflective equilibrium (which he takes practice-dependence to be a part of). Quite the contrary: The application model is a central part of reflective equilibrium, which precisely requires theorists to derive normative implications from general principles through application. The noted problematic features of practice-dependence are due to the claim that justice is constrained by existing institutions. But this assignment of priority to existing institutions is itself a form of foundationalism in tension with reflective equilibrium, which requires all judgments to be open to revision.

So my suggestion is that the problems with practice-dependence are due to an artificial dichotomy which mis-characterises the alternatives. The real alternative includes the application model but is not committed to the kinds of a priori fact-denial that Sangiovanni seems to think, since reflective equilibrium precisely proceeds by adjusting principles and judgments about cases in a process including facts about institutions both as objects of application and as objects of considered judgments, but where institutions do not have the priority assigned to them by the practice-dependence thesis. Political theory should therefore consider application and justification together; interpretation of facts is part of the justification of normative principles precisely because application and justification are not separate exercises. This perspective accepts most of the thoughts behind the practice-dependence thesis, understood as a way of explicating how reflective equilibrium works, but without making the noted problematic assumptions.

\section{References}

Dworkin, R., 2011. Justice for hedgehogs. Cambridge, MA: Harvard University Press.

Favell, A., 2014. Multicultural citizenship in theory and practice: Applied political philosophy in empirical analyses. In: A. Favell, ed. Immigration, integration and mobility. Colchester: ECPR Press, 21-40.

Hall, E., 2015. How to do realistic political theory (and why you might want to). European journal of political theory, published online March 23, 2015, DOI: 10.1177/1474885115577820

James, A., 2005. Constructing justice for existing practice: Rawls and the status quo. Philosophy \& public affairs, 33 (3), 281-316.

Lægaard S., 2012. Unequal recognition, misrecognition and injustice: The case of religious minorities in Denmark. Ethnicities, 12 (2), 197-214.

Lægaard, S., 2015. Multiculturalism and contextualism: How is context relevant for political theory? European journal of political theory, 14 (3), 259-276.

Meckled-Garcia, S., 2013. The practice dependence red herring and better reasons for restricting the scope of justice. Raisons politiques, 51 (3), 97-120. 
Miller, D., 2013. Two ways to think about justice. In: D. Miller, ed. Justice for earthlings. Oxford: Oxford University Press, 40-69.

Rawls, J., 1999. A theory of justice. Revised edition. Cambridge, MA: Harvard University Press.

Sangiovanni, A., 2008. Justice and the priority of politics to morality. Journal of political philosophy, 16 (2), 137-164.

Sangiovanni, A., 2016. How practices matter. Journal of political philosophy, 24 (1), 3-23.

Valentini, L., 2011. Global justice and practice-dependence: Conventionalism, institutionalism, functionalism. Journal of political philosophy, 19 (4), 399-418.

Walzer, M., 1983. Spheres of justice. Oxford: Martin Robertson.

Williams, B., 2005. In the beginning was the deed, ed. G. Hawthorn. Princeton: Princeton University Press. 